1. Assistant Professor Anesthesiology \& ICU,

Liaquat University of Medical and Health Sciences Jamshoro.

2. Assistant Professor Anesthesiology and ICU,

Dow University of Health Sciences, Civil Hospital Karachi.

3. Consultant Anesthetist,

Dow University of Health Sciences, Civil Hospital Karachi.

4. MBBS, House officer, DUHS, Civil Hospital Karachi.

5. Research Fellow.

Correspondence Address:

Dr. Ahmed Ali,

Research Fellow Karachi.

A - 139 Block i North Nazimabad Karachi

doctor.karachi@gmail.com

Article received on: 26/10/2015

Accepted for publication:

09/12/2015

Received after proof reading

09/02/2016

\section{SPINAL ANESTHESIA; \\ LOWER SEGMENT CESAREAN SECTION COMPARISON OF ATIENTS WITH HYPERBARIC BUPIVACAINE VERSUS ISOBARIC BUPIVACAINE AS USED FOR SPINAL ANESTHESIA.}

\section{Dr. Hamid Raza1, Dr. Bashir Ahmed ${ }^{2}$, Dr. Kamlaish ${ }^{3}$, Dr. Saqib Basr ${ }^{4}$, Dr. Ahmed Ali ${ }^{5}$}

ABSTRACT... Objective: The purpose of the study is to compare and assess the sensory and motor block along with the associated hemodynamic changes that occur in the patient population operated for a lower segment cesarean section (LSCS), when they are given $0.5 \%$ hyperbaric bupivacaine versus $0.5 \%$ isobaric bupivacaine as used for spinal anesthesia. Study Design: Prospective double blind randomized trial. Period: 6 months duration from April 2014 to September 2014. Setting: A tertiary care hospital in the city of Karachi, Pakistan. Method: The study population consisted of 60 patients belonging to the ASA 1 and ASA 2 category, who underwent a lower segment cesarean section, and comparative analysis of the efficacy and associated hemodynamic changes of hyperbaric with isobaric bupivacaine. The patient population was segmented into two groups both groups containing 30 patients, group A receiving hyperbaric bupivacaine $0.5 \%$ as $2.5 \mathrm{ml}(12.5 \mathrm{mg}$ dose ) and the second group designated as, group $B$ receiving isobaric bupivacaine $0.5 \%$ as $2.5 \mathrm{ml}$ ( $12.5 \mathrm{mg}$ dose) intrathecally. The resultant sensory and motor blockade was determined using pin prick and bromage scale respectively. Results: There was a significant difference found among the two groups under study, when compared at $3 \mathrm{~min}$ interval regarding the sensory blockade. The level of T6 block was reached in 33.33\% $(n=10)$ patients belonging to group $A$ and $56.66 \%(n=17)$ patients in group B. It was observed that there was no significant change among the two groups at $5 \mathrm{~min}$ interval regarding sensory and motor blockade respectively. The immediate sensory blockade with isobaric bupivacaine in group B produced greater decrease in the systolic and mean arterial blood pressure when contrasted with hyperbaric bupivacaine in group $A$ at $5 \mathrm{~min}$ interval, but after time interval of $45 \mathrm{~min}$ there was no statistically significant change observed. Conclusions: According to our study the effects of isobaric bupivacaine were more significantly predictable; hence have a higher efficacy, when contrasted against hyperbaric bupivacaine in lower section cesarean section spinal anesthesia. Quick sensory blockade with isobaric bupivacaine was associated with more decrease in blood pressures when contrasted with the hyperbaric bupivacaine, but this result is not statistically significant.

Key words: Lower segment cesarean section, Spinal anesthesia, hyperbaric bupivacaine, isobaric bupivacaine.

Article Citation: Raza H, Ahmed B, Kamlaish, Basr S, Ali A. Spinal anesthesia; Lower segment cesarean section comparison of atients with hyperbaric bupivacaine versus isobaric bupivacaine as used for spinal anesthesia.Professional Med $\mathrm{J}$ 2016;23(2):161-165. DOI: 10.17957/TPMJ/16.3147

\section{INTRODUCTION}

One of the most common, safe and popular technique for the production of anesthesia in patients operated for a lower segment cesarean section and/or lower abdominal surgery is spinal anesthesia if no contraindication exists. ${ }^{1}$ Bupivacaine and its various combinations with or without glucose is being used, however the dose of anesthetic decreases due to the physiologic changes in pregnancy and may also cause unpredictable sensory block. ${ }^{2}$ One of the major determinants of the dispersion of drug in the subarachnoid space and the level of blockade produces is its baricity. ${ }^{2,3}$ Numerous researches have studied and compared the efficacy of isobaric versus hyperbaric bupivacaine which is used in various surgeries, like obstetric, orthopedic, and transurethral surgeries. ${ }^{4,5,6}$ But the data remains largely inconclusive when it comes to the superiority of drug used..$^{7,8,9} \mathrm{We}$ studied $0.5 \%$ hyperbaric and $0.5 \%$ isobaric bupivacaine used in same volume and dosage, 
for patients undergoing cesarean section to compare and contrast the efficacy and associated hemodynamic changes produced by both of the drugs.

\section{METHODS}

The method of study is a prospective double blind randomized trial, the study was conducted for a period of 6 months duration from April 2014 to September 2014, the study population consisted of 60 patients belonging to the ASA 1 and ASA 2 category, who underwent a lower segment cesarean section, a written informed consent was signed by all patients. The exclusion criteria was patients who had a contraindication for spinal anesthesia, ASA grade 3 and 4, hypertensive, hypotensive and eclamptic patients. The procedure was fully explained to the patients. A random number generator was used to divide the patients into two groups of 30 patients each. Group A received hyperbaric bupivacaine $0.5 \%$ and group $B$ received isobaric bupivacaine $0.5 \%$. All patients received ringers lactate solution at $15 \mathrm{ml} / \mathrm{kg}$ intravenously under standard monitoring. Heart rate, blood pressure both the systolic and diastolic values and mean arterial pressures were noted. The method of choice for sensory and motor system blockade assessment were described to the patients before the anesthesia. In all patients spinal anesthesia was performed using a $25 \mathrm{G}$ spinal needle in a sitting position at the level of L3-L4 intervertebral space. Patients in group A received $2.5 \mathrm{ml}$ approx $12.5 \mathrm{mg}$ of hyperbaric bupivacaine $0.5 \%$ and group $B$ received $2.5 \mathrm{ml}$ approx $12.5 \mathrm{mg}$ of isobaric bupivacaine $0.5 \%$. The time of the whole amount of drug delivered was considered as "Time zero". Heart rate, level of sensory and motor blockade and blood pressure was assessed after the patient was turned supine with a 15 degree tilt to the left lateral side. To check the sensory block the pin prick method was used, along the imaginary mid clavicular line till the sensory blockade reached a level of sensory dermatome T6 level, after which the surgical procedure was allowed. Modified bromage scale was the method of choice to assess the motor block, from 0 to 3, 0 being no motor block, 1 being unable to perform a extended leg raise but able to move both knees and both the feet, 2 being unable to perform an extended leg raise and move knees but able to move feet, 3 being a complete motor blockade of both the lower limbs, no movement at all. A score of greater than 2 is considered significant motor block. The assessments were made at first, second, third and five minutes at first and then at 5 minutes intervals until the procedure was done and then at 15 minutes until complete return of the sensory and motor function. Hypotension which is defined as a fall in systolic blood pressure to more than $20 \%$ from baseline reading noted, was treated with injection of ephedrine $6 \mathrm{mg}$ bolus injection. And bradycardia (heart rate of less than 55 beats/min) was treated with $0.4 \mathrm{ng}$ injection of atropine. The data was analyzed using SPSS version 19. Demographic data was expressed as mean +/- standard deviation. Chi square test was used to analyze variables such as level of blockade, onset of the resultant sensory and motor block. A p value of $<0.05$ was considered statistically significant.

\section{RESULTS}

The bio data of the groups of patients included their age, weight and ASA status. There was no significant change whatsoever in sensory blockade in the patients at the 1 minute interval $(p=0.435)$ as it blockade occurred in $n=6$ patients in Group B and $n=4$ patients in Group A. Upon reaching the three minute mark a significant contrasting finding was noted $(p=0.019)$. A total number of $n=17$ patients reached a level of blockade till sensory level thoracic 6 (T6) in Group $B$ as contrasted with $n=10$ patients in group $A$ reached this level of blockade. Thoracic 8 (T8) level blockade was observed in $n=10$ patients in group $A$ and $n=3$ in group $B$ respectively. $A$ level of thoracic 10 (T10) blockade was observed in $n=7$ patients in group $A$ and $n=2$ patients in group $B$ (Fig 1). At $5 \mathrm{~min}$ there was no significant change $(p=0.801)$ as $n=6$ patients acquired a good sensory blockade in Group A among them $\mathrm{n}=2$ reached at a level of thoracic 6 (T6). In Group $B$ only $n=1$ patient reached level of thoracic 6 (T6) and $n=1$ at a level of thoracic 8 (T8) Table I. 
Motor block: The loss of motor functions or motor block was observed in a total of $n=4$ patients in Group A and in $n=6$ patients in Group B after 1 min interval. Upon reaching the five minute mark the loss of motor function was seen in $n=20$ patients in Group A and $n=22$ patients in Group B. No statistically significant change was observed $p=0.343$ (fig 2) Ephedrine the drug used to treat hypotension had the same effect among the two groups $(p=0.260)$. Changes in heart rate showed alteration in the two patient population at $45 \mathrm{~min}(p=0.399)$. Significant changes were seen in systolic blood pressures as they drop in group B within 5 min $(p=0.010)$ but after 45 min there was no change when both groups are compared $(p=0.086)$. Diastolic blood pressures did not reflect any change within $5 \mathrm{~min}(p=0.118)$ and after 45 min among both groups of patients under study ( $p=0.585$ ) (Fig.6). No change was observed in Mean arterial pressure after $45 \mathrm{~min}$ $(p=0.457)$.

\begin{tabular}{|l|c|c|c|}
\hline Time Interval & $\begin{array}{c}\text { Group } \\
\text { A }\end{array}$ & $\begin{array}{c}\text { Group } \\
\text { B }\end{array}$ & $\begin{array}{c}\text { p } \\
\text { value }\end{array}$ \\
\hline Motor block & & & \\
\hline At 1min time interval & 4 & 6 & 0.435 \\
\hline At 5min interval & 20 & 22 & 0.343 \\
\hline Sensory block & & & \\
\hline At 1min time interval & 4 & 6 & 0.435 \\
\hline At 3min interval (T6 level) & 10 & 17 & 0.019 \\
\hline At 3min interval (T8 level) & 10 & 3 & \\
\hline At 3min interval (T10 level) & 7 & 2 & \\
\hline At 5min interval & 6 & 2 & 0.801 \\
\hline Use of ephedrine & & & \\
\hline $\begin{array}{l}\text { Ephedrine injected in } \\
\text { patients }\end{array}$ & 7 & 11 & 0.260 \\
\hline
\end{tabular}

Table-I. Achievement of Motor \& Sensory Block, and ephedrine use among the patient population

\begin{tabular}{|c|c|c|c|c|c|}
\hline & N & Mini. & Maxi. & Mean & Std. Deviation \\
\hline Age (Yrs) & 60 & 21 & 40 & 28.47 & 4.098 \\
\hline Weight(kg) & 60 & 50 & 80 & 69.52 & 7.347 \\
\hline
\end{tabular}

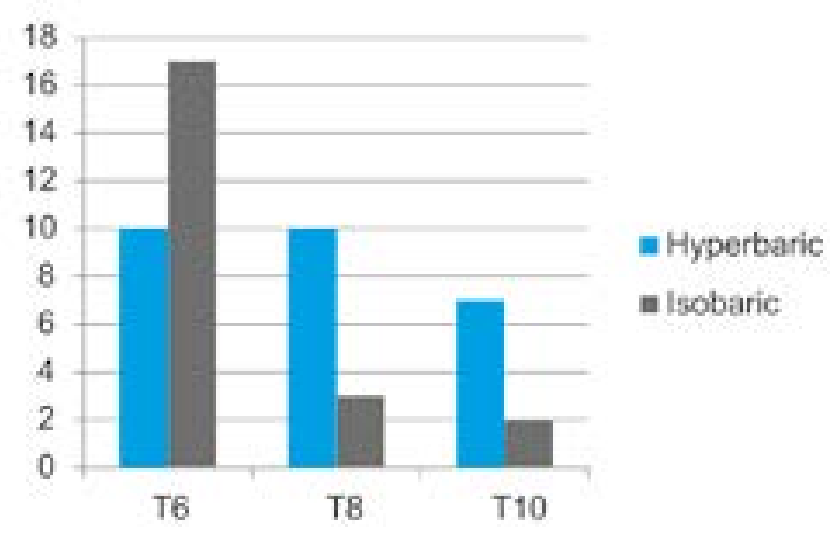

Fig-1. Sensory block at $3 \mathrm{~min}$

\section{DISCUSSION}

Spinal anesthesia is one of the most frequently used technique for anesthesia in lower segment cesarean section. The baricity of the drug is the factor responsible for the duration and diffusion capacity of the local anesthetic used. In obstetrics the hyperbaric solutions are used and preferred as they are unable to reach higher thoracic levels and thus cause less side effects, as compared

Fig-2.

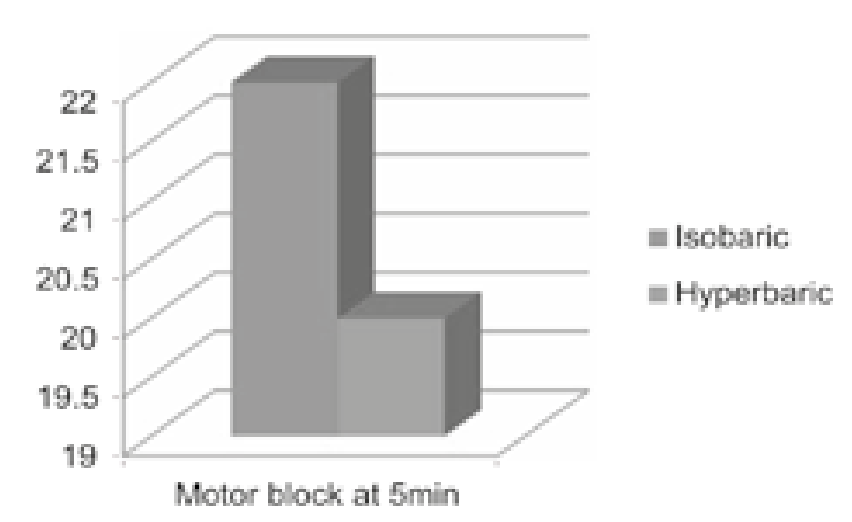

to isobaric solutions, that reach a higher sensory level. ${ }^{10}$

The study was conducted to predict whether the choice of drug used in spinal anesthesia would affect the quality of anesthesia and the hemodynamic changes that occur. Comparing the drug of two different baricity and same volume and dose, we notice that sensory blockade was 
achieved quickly among the isobaric group (T6 level) at $3 \mathrm{~min}$ that shows a significant difference $(p=0.019)$. At $5 \mathrm{~min}$ virtually no change was observed. Motor blockade was observed at $5 \mathrm{~min}$ but without any change $(p=0.343)$. These results differ from the study by solakovic. ${ }^{11}$ In their study the patients receiving hyperbaric bupivacaine had higher sensory block at a level of thoracic five ( T5 ) and with the isobaric group at T10, and lead to a block which is at a higher dermatome with more associated hemodynamic changes observed in some of the patients under study. A recent study observed a shorter duration of time for peak in sensory blockade in hyperbaric group versus isobaric group. ${ }^{12}$ We did not observe any change in decrease of heart rate among the two groups at $45 \mathrm{~min}$ interval $(p=0.399)$. There was a drop in systolic blood pressure and mean arterial pressure in group $B$ within $5 \mathrm{~min}(p=0.010$, $p=0.028$ ) when compared with group $A$. There was no change in systolic blood pressure and mean arterial pressure after $45 \mathrm{~min}(p=0.086$ and $p=0.457$ ), and there was no decrease in diastolic blood pressure at $5 \mathrm{~min}$ interval $(p=0.118)$ and 45 min interval $(p=0.585)$ in both groups $A$ and $B$. The hypertensive drug Ephedrine was given to 23.3\% $n=7$ patients in group $A$ and $36.6 \% n=11$ patients in isobaric group, the difference was not statistically significant $(p=0.260)$. A study done in 2000 by Rene Martin matches our results. ${ }^{13}$ According to their study motor and sensory block was seen to develop quickly ( $5 \mathrm{~min}$ ) in the isobaric group $(p<0.05)$. However the hemodynamic changes reported in their study are different. According to their study there was a significant drop in mean arterial pressure observed in both groups and it being more significant in hyperbaric group, where as our study shows greater drop in isobaric group. In another local study rapid onset of hemodynamic changes were seen when using hyperbaric bupivacaine as compared to isobaric bupivacaine for caesarean section. ${ }^{14}$ According to study by Punshi GD et al, who compared hyperbaric bupivacaine with plain bupivacaine and found no statistically significant difference in the onset of block, time required to achieve maximum blockade, the level of block and the hemodynamic parameters. ${ }^{15}$ The results are similar to our study.

\section{CONCLUSION}

According to our study the effects of isobaric bupivacaine were more significantly predictable; hence have a higher efficacy, when contrasted against hyperbaric bupivacaine in lower section cesarean section spinal anesthesia. Quick sensory blockade with isobaric bupivacaine was associated with more decrease in blood pressures when contrasted with the hyperbaric bupivacaine, but this result is not statistically significant.

Copyright (C) 09 Dec, 2015.

\section{REFERENCES}

1. Gogartewn W, Van Aken H. "A century of regional analgesia in obstetrics". Anesth Analg 2000; 91:773-5.

2. das Neves JF, Monteiro GA, de Almeida JR, Brun A, Cazarin N, Sant'Anna RS, Duarte ES. Spinal anesthesia for cesarean section: comparative study between isobaric and hyperbaric bupivacaine associated to morphine. Rev. Bras. Anestesiol. 2003; 53(5): 573-578.

3. Imbelloni LE, Moreira AD, Gaspar FC, Gouveia MA, Cordeiro JA. Assessment of the densities of local anesthetics and their combination with adjuvants. An experimental study. Rev. Bras. Anestesiol. 2009; 59(2):154-65.

4. G. Cappelleri, G. Aldegheri, G. Danelli Et. Al. "Spinal Anesthesia with Hyperbaric Levobupivacaine and Ropivacaine for outpatient Knee Arthroscopy: a prospective, randomized, double blind Study", Anesthesia and Analgesia, 2005 101(1): 77-82.

5. H. Sen, T. Purtuloglu, A. Sizlan ET Al. Comparison of intrathecal hyperbaric and isobaric levobupivacaine in urological surgery," Minerva Anestesiologica, vol. 76, No. 1, pp. 24-28, 2010.

6. G. Hocking, J. A. W. Wildsmith, Intrathecal drug spread," British Journal of Anesthesia, Vol 93, No. 4, pp. 568-578,2004.

7. F. Gori, F. Corradetti, V. Cerotto, and V. A. Peduto. Influence of positioning on plain levobupivacaine Spinal Anesthesia in Cesarean section," Anesthesiology Research and Practice, vol. 2010, Article ID 212696, 2010.

8. G. Danelli, M. Baciarello, S. Di Cianni Et Al., "Effects of baricity of $0.5 \%$ or $0.75 \%$ levobupivacaine on the onset time of spinal anesthesia: a randomized trial," Canadian Journal of Anesthesia, vol. 55, No.8, pp. 501- 
506, 2008.

9. Veering BT, Immink Spect TM, Burn AG, Stienstra $\mathrm{R}$, Vankleef JW., "Spinal Anesthesia with $0.5 \%$ hyperbaric bupivacaine in elderly patients" Effects of duration spent in sitting position. $\mathrm{Br} \mathrm{J}$ Anesth 2001 ;87 : 738-42.

10. Srivastava U, Kumar A, Gandhi NK, Saxena, Dutta D, Chandra P, Singh S. Hyperbaric or plain bupivacaine combined with fentanyl for spinal anaesthesia during caesarean delivery Indian J. Anaesth 2004;48(1):44.

11. N. Solakovic, Level of sensory block and baricity of bupivacaine $0.5 \%$ in spinal Anesthesia" Medicinski Arhiv, 2010;64(3): 158-160.

12. Xu L, Guo QL, Yan JQ. Isobaric and hyperbaric local anesthesia used in spinal anesthesia, Zhong $\mathrm{Nan} \mathrm{Da}$ Xue Xue Bao Yi Xue Ban, vol. 30, no. 3, pp. 325-327, 2005.

13. Rene Martin, Chantal Frigon, Angelo Chretien, JeanPierre., "Onset of spinal block is more rapid with isobaric than hyperbaric bupivacaine CJA 2000; 47: 436.

14. Sadqa Aftab, Hamid ALI, Safia Zafar, Murtaza Sheikh, Tipu Sultan., Intrathecal isobaric versus hyperbaric bupivacaine for elective cesarean section." Pak J Surg $2007 ; 23$ (4) : 296-301.

15. Punshi GD, Afshan G, "Spinal anaesthesia for caesarean section: plain vs hyperbaric bupivacaine." J Pak Med Assoc, 2012 Aug;62(8):807-11.

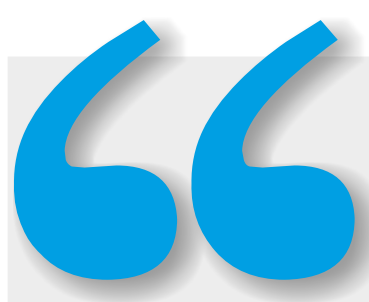

\section{"It does not matter how slowly you go as long as you do not stop."}

\section{Confucius}

\begin{tabular}{|c|c|c|c|}
\hline \multicolumn{4}{|c|}{ AUTHORSHIP AND CONTRIBUTION DECLARATION } \\
\hline Sr. \# & Author-s Full Name & Contribution to the paper & Author $=\mathbf{s}$ Signature \\
\hline 1 & & $\begin{array}{l}\text { Concept, Analysis, Writeup, } \\
\text { Drafting, Layout }\end{array}$ & \\
\hline 2 & Dr. Bashir Ahmed & $\begin{array}{l}\text { Concept, Drafting, } \\
\text { Statistical analysis }\end{array}$ & \\
\hline 3 & Dr. Kamlaish & $\begin{array}{l}\text { Concept, Drafting, } \\
\text { Statistical Analysis }\end{array}$ & \\
\hline 4 & Dr. Saqib Basr & $\begin{array}{l}\text { Write-up, Data collecting, } \\
\text { Final layout }\end{array}$ & $\hbar$ \\
\hline 5 & Dr. Ahmed Ali & $\begin{array}{l}\text { Write up, Data collection, } \\
\text { Final layout }\end{array}$ & \\
\hline
\end{tabular}

